\title{
LA PARADOJA DE LA ADICIÓN: RESPUESTA AL MAESTRO MARGÁIN
}

MARIO BUNGE

Universidad Nacional

Autónoma de México

El Dr. Tom Settle por carta, y el maestro Hugo Margáin en Crítica, Vol. VI, No. 18, han señalado un error imperdonable en mi nota sobre lo que yo llamo la paradoja de la adición, aparecida en Crítica, Vol. III, No. 9. Afortunadamente el error está en el malhadado ejemplo, no en la tesis general de la nota.

Según el principio de adición, de la lógica matemática, de $p$ se sigue $p$ ó $q$, donde $p$ y $q$ son proposiciones que no tienen por qué tener parentesco alguno, sintáctico, semántico o pragmático. Contrariamente a lo afirmado en mi nota, la negación de $q$ no prueba $\mathrm{p}$, ya que ésta ya había sido afirmada. Hasta aquí, el principio es inocente y yo culpable. Pero lo importante, y ésta es la tesis de mi nota, es que el principio de adición tolera inferencias ilegítimas, tales como

... México está en América.

... México está en América o no tengo ganas de pensar.

... Si tengo ganas de pensar, México está en América.

Esta es una falacia porque la conclusión afirma el error consistente en que, para que yo tenga ganas de pensar, es necesario que México esté en América ( 0 , lo que es equivalente, basta que yo tenga ganas de pensar para que México se ubique en América). La falacia consiste en ampliar el universo del discurso originario (la clase de referencia de p) agregando la clase de referencia de $q$. Este paso, sintác. ticamente legítimo, puede no serlo semánticamente, ya que, si introduce irrelevancias, puede causar confusión o error. 
Las falacias de este tipo no son pocas ni siempre inocuas o fáciles de poner al descubierto. Son tan frecuentes como dañinas en física relativista y en física cuántica, donde el principio de adición tolera la introducción subrepticia del sujeto cognoscente y con ello el abandono de la objetividad científica. Por ejemplo, sea un enunciado nomológico de la forma " $y=f(x)$ ", donde $x$ e $y$ son variables reales que representan sendas propiedades físicas, y $f$ una función que las relaciona. El principio de adición autoriza la inferencia de la fórmula anterior a esta otra: "Si observo o mido $x$ e $y$, entonces $y=f(x)$ ". De este modo un enunciado de ley física se convierte en una proposición concerniente a un sistema físico y a un sujeto (o sea, se transforma en un enunciado nomopragmático). Las transformaciones de Lorentz, las desigualdades de Heisenberg y muchas otras fórmulas científicas han sufrido metamorfosis semejantes al amparo del principio de adición.

Es obvio que hay que remediar esta situación. Es igualmente claro que el remedio no consiste en extirpar el prin. cipio, puesto que se lo necesita diariamente. (Tan es así que Anderson (1972) lo conserva en el cálculo de relevancia que propone. Por este motivo dicho cálculo no evita automáticamente las irrelevancias, de modo que no cumple lo que promete.) Lo que hay que hacer es vigilar las aplicaciones del principio para evitar las falacias que permite. Hay dos maneras de evitar estas falacias. Una es limitarse a trabajar en contextos axiomáticos, ya que en éstos no se admiten predicados que no figuren entre los primitivos o que no sean definidos correctamente en términos de éstos. Pero tal limitación, deseable en la etapa final de la fundamentación. sería paralizante en la etapa constructiva.

La segunda manera de evitar las falacias semánticas cometidas con la complicidad del principio de adición es montar guardia para evitar el contrabando de predicados extraños al universo del discurso originario. Esto es lo que se hace, por ejemplo, al enunciar con algún cuidado el teorema de inter- 
polación de Craig: "Si $p$ implica a $q$, entonces existe una proposición $r$, que no contiene predicados diferentes de los que figuran en $p$ y $q$, y tal que $p$ implica a $r$, y $r$ implica a q." La cláusula subrayada expresa la condición que he llamado de clausura (u homogeneidad) semántica.

Lo mismo vale para los imperativos si se acepta la tesis de su traducibilidad (semántica, no necesariamente pragmática) a enunciados declarativos. (Ejemplo: ' $i$ Cierra la puerta!' se traduce por 'El sujeto recibe la orden de cerrar la puerta', o 'El actor ordena se cierre la puerta.') Para el problema de la traducibilidad de los imperativos nos remitimos a Marhenke (1950) y Searle (1969).

En resumidas cuentas creo que, pese al error señalado por mis críticos, mi nota $(a)$ llama la atención sobre una falacia semántica que no he visto tratada por otros autores, y que se comete tanto en el discurso ordinario como en el científico, y $(b)$ muestra cómo evitar dicha falacia, respetando así un principio de la lógica aristotélica olvidado durante el periodo, ya superado, de la euforia formal.

Para un tratamiento más amplio de la cuestión me remito a Bunge (1974), capítulo 2.

\section{REFERENCIAS}

Anderson, A. R. (1972). An intensional interpretation of truthvalues. Mind 81, pp. 348-371.

Bunge, M. (1974). Sense and Reference. Dordrecht y Boston: D. Reidel Publishing Company.

Marhenke, P. (1950). The criterion of significance. En L. Linsky, compilador, Semantics and the Philosophy of Language Urbana, Ill., University of Illinois Press, 1952.

Searle, J. (1969). Speech Acts: An Essay in the Philosophy of Language. Cambridge, University Press. 